\title{
NEUTRON DIFFRACTION STUDIES ON RECRYSTALLIZATION OF SOLUTION DERIVED LEAD ZIRCONATE TITANATES
}

\author{
B. MOROSIN*, A. C. LAWSON**,G.H. KWEI***,J. A. VOIGT*, and B. A. TUTTLE* \\ *Sandia National Laboratories, Albuquerque, NM 87185-0345 \\ **Los Alamos National Laboratory, Los Alamos, NM 87545 \\ ***Lawrence Livermore National Laboratory, Livermore, CA 94550
}

\begin{abstract}
We performed neutron powder diffraction on solution-derived lead zirconate titanates (PZT). Three compositions, PZT 45/55, PZT 20/80 and $\mathrm{PbTiO}_{3}$, were investigated. The materials were annealed so that the perovskite phase had just begun to grow from the precursor phase. In our materials this precursor phase is the pyrochlore rather than fluorite phase. The results show that in the pyrochlore phase, the $(\mathrm{Ti}, \mathrm{Zr})$ and the $\mathrm{Pb}$ are ordered in their crystallographic sites while the $\mathrm{O}$ are essentially disordered in both of the two usual pyrochlore anion sites.
\end{abstract}

\section{INTRODUCTION}

Thin films of PZT materials are of commercial interest for various applications which make use of their piezoelectric, ferroelectric and dielectric properties. Recent studies on the microstructural evolution of solution-derived lead zirconate titanates have shown that phase evolution often proceeds from an amorphous to a crystalline material above about $400^{\circ} \mathrm{C}[1]$. Our earlier work has shown that for our solution system with PZT 20/80, a pyrochlore phase with an extremely small crystallite size as shown by the very broad $\mathrm{x}$-ray diffraction maxima is formed near $\sim 425^{\circ} \mathrm{C}$, and this phase transforms to the perovskite phase at approximately $475^{\circ} \mathrm{C}$. The nano scale perovskite growth rate is dependent on the orientation of the pyrochlore grains, with the perovskite (101) planes appearing as a fast growth direction aligned along pyrochlore (111) planes. Attempts to understand the growth mechanism initiated the question of the degree of order in such nano sized crystalline grains of the pyrochlore phase. Neutron diffraction would be an excellent probe provided sufficient material were available; hence, bulk samples using the identical precursors to those of the PZT thin films were prepared. The preparation of these gelderived bulk samples was adjusted so as to obtain $\mathrm{x}$-ray diffraction patterns which mimicked those of the PZT films. Crystallization temperatures were approximately $50^{\circ} \mathrm{C}$ lower for the gelderived bulk PZTs than for films.

On a broader scope it was also hoped that some information might also reflect on the question of the nature of the pyrochlore phase since several reports suggest that the initial phase grown from the solution-derived amorphous state really is a fluorite-type structure [2-4]. These studies appeared to show that no superlattice peaks were seen in the x-ray or electron diffraction data, leading to the conclusion that the unit cell for the phase was cubic or psuedo-cubic with 


\section{DISCLAIMER}

Portions of this document may be illegible in electronic image products. Images are produced from the best available original document. 
a $\sim 5.25 \AA$ for the titanate material and with a somewhat larger cell for the zirconium-containing material. There is, of course, a close relationship between the pyrochlore and the fluorite structure-types. The pyrochlores are usually formulated as $\mathrm{A}_{2} \mathrm{~B}_{2} \mathrm{X}_{7}$ in a face centered cell with a $10.5 \AA$ edge containing eight formula units. This can be described as a cation-ordered, anionvacancy arrangement for a fluorite-like supercell with twice its usual cell edge. It should be noted, however, that the detailed ordering results in eight-coordinated and six-coordinated cations, usually designated as the A and B cations, repectively, since the anions occupy two different crystallographic sites, one a 48 -fold and the other an 8-fold site.

Here we report on the Rietveld structure refinement of neutron diffraction data for three samples which were annealed to the point that the sharper perovskite phase peaks, together with the broader pyrochlore phase peaks, appeared so as to serve as an internal marker. X-ray diffraction of the PZT $20 / 80$ material is essentially identical to that obtained on $3000 \AA$ films of this composition deposited on $\mathrm{MgO}$.

\section{EXPERIMENTAL}

Solution derived samples were prepared to simulate in condition as closily possible the previously films studied at the PZT 20/80 composition[5] and were extended to two other compositions ( $\mathrm{PZT} 45 / 55, \mathrm{PbTiO}_{3}$ ) in order to determine if $\mathrm{Zr}$ concentration was important. Solutions were prepared by the inverted mixing order (IMO) process developed by Schwartz et al. [6] which is a modification of a hybrid solution deposition process developed by Sayer and coworkers [7]. The slight excess of $\mathrm{Pb}(5 \mathrm{~mole} \%)$ employed in previous work on preparation of oriented PZT 20/80 films was added in order to be consistent with previous studies.[5] Various annealing temperature and times were investigated in order to just form the perovskite phase as a marker for the neutron studies, yet not alter the $\mathrm{x}$-ray diffraction pattern for the pyrochlore phase.

Neutron powder diffraction data for the three samples were collected at room temperature on the high-resolution ( $\delta \mathrm{d} / \mathrm{d}=1 \times 10^{-3}$ for the $150^{\circ}$ detector banks) neutron powder diffractometer (GPPD) at IPNS. Data were collected simultaneously in three sets of detector banks (at $2 \theta=$ $150^{\circ}, 90^{\circ}$, and $60^{\circ}$ ) for approximately 3 hours at an average proton current of $13 \mathrm{~mA}$ at $20 \mathrm{~Hz}$. A standard 3/8-in diameter vanadium sample tube was used in the automatic sample changer configuration.

\section{STRUCTURAL REFINEMENTS AND RESULTS}

The structural models were refined using the neutron powder data with the Rietveld refinement code GSAS developed by Larson and VonDreele[8]. In addition to the usual instrument parameters, the initial refinement employed parameters known for the two phases; however, the metal ions in both phases were given parameters to allow mixed occupancy and the occupancy for the two crystallographic different oxide ions in the pyrochlore phase were allowed to vary. Since the lines were broadened much more than is usually expected for normal powder data, the crystallite size parameters were initially set to values suggested by earlier high resolution 
Fig. 1. Rietveld refinement for $\mathrm{PbTiO}_{3}$. The data are from the $\pm 90^{\circ}$ detector banks of GPPD at IPNS. The points are the measured data, the line through the points is the Rietveld fit, and the lower curve is their difference. The lower set of tic marks shows the positions of allowed reflections for the perovskite phase; the upper set is for the pyrochlore phase.

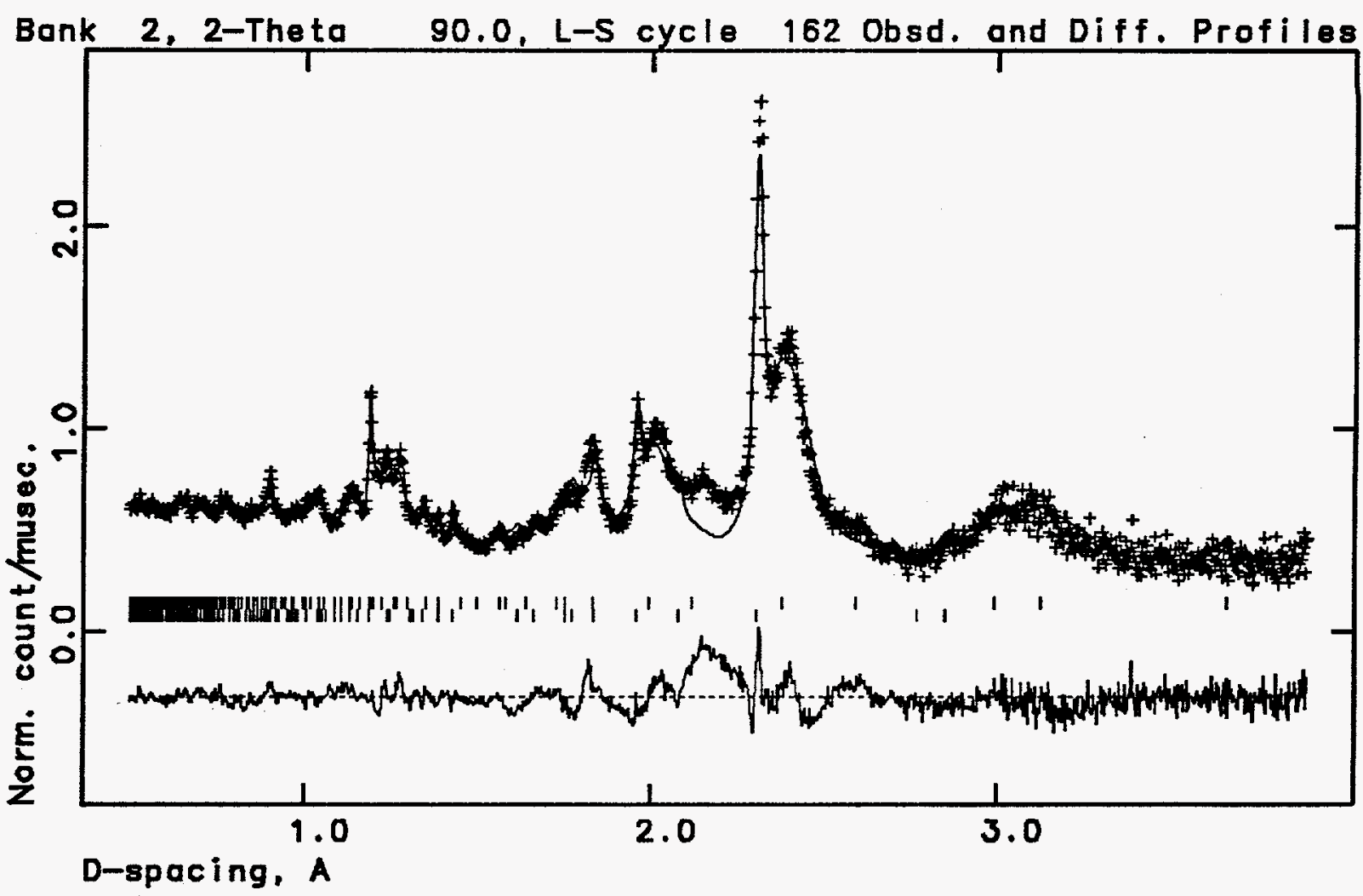

electron diffraction results. Strain was initially neglected and subsequent attempts to refine an additional parameter to include such a contribution proved difficult due to the high correlation with other parameters hampering convergence of the refinement model. In fact the size parameter and the volume fraction of the phase are also highly correlated so those parameters may be susceptible to systematic error. The size parameter also accounts for whatever strain broadening is present, and the refined values should not be taken too seriously. In addition after crystallite size line broadening parameters were under control in these 'pyrochlore' refinements, the data were refined with a defective fluorite-type structure; however, these attempts were unsuccessful.

The refinements in which the cation parameters were allowed to vary so as to permit solid solution of the $\mathrm{Pb}$ and the $(\mathrm{Ti}, \mathrm{Zr}$ ) clearly showed a preference for ordering (within three standard deviations) for all three compositions. Table I list the final parameters for our refinement model which included overall isotropic thermal parameters and size parameters for the two phases, parameters to determine the amounts of the two phases and occupancy parameters for the two crystallographic $\mathrm{O}$ positions (labeled consecutively so as to avoid confusion) in the pyrochlore phase. Figures 1,2 and 3 show typical data and the fit for the three compositions. It is noted that at $d=2.1$ and 2.5 there appears small peaks which are not fit. These are not due to any of the known phases of $\mathrm{Pb}$ oxides, a material which was present in slight excess. The agreement appears satisfactory considering the broad line profiles which were being fit.

Note the occupancy parameters for $\mathrm{O} 3$ and $\mathrm{O} 4$ correspond to nearly random, but slightly ordered, arrangements (values of 0.86 and $0.84=6 \times 0.14$ would be exactly random) with the sum of the two independent parameters summing to about 1.0 ( $1 / 6 \times$ pp of $\mathrm{O} 4+\mathrm{pp}$ of O3). 
Fig. 2. Rietveld refinement for $\mathrm{PbZr}_{\mathrm{x}} \mathrm{Ti}_{1-\mathrm{x}} \mathrm{O}_{3}, \mathrm{x}=0.20$.

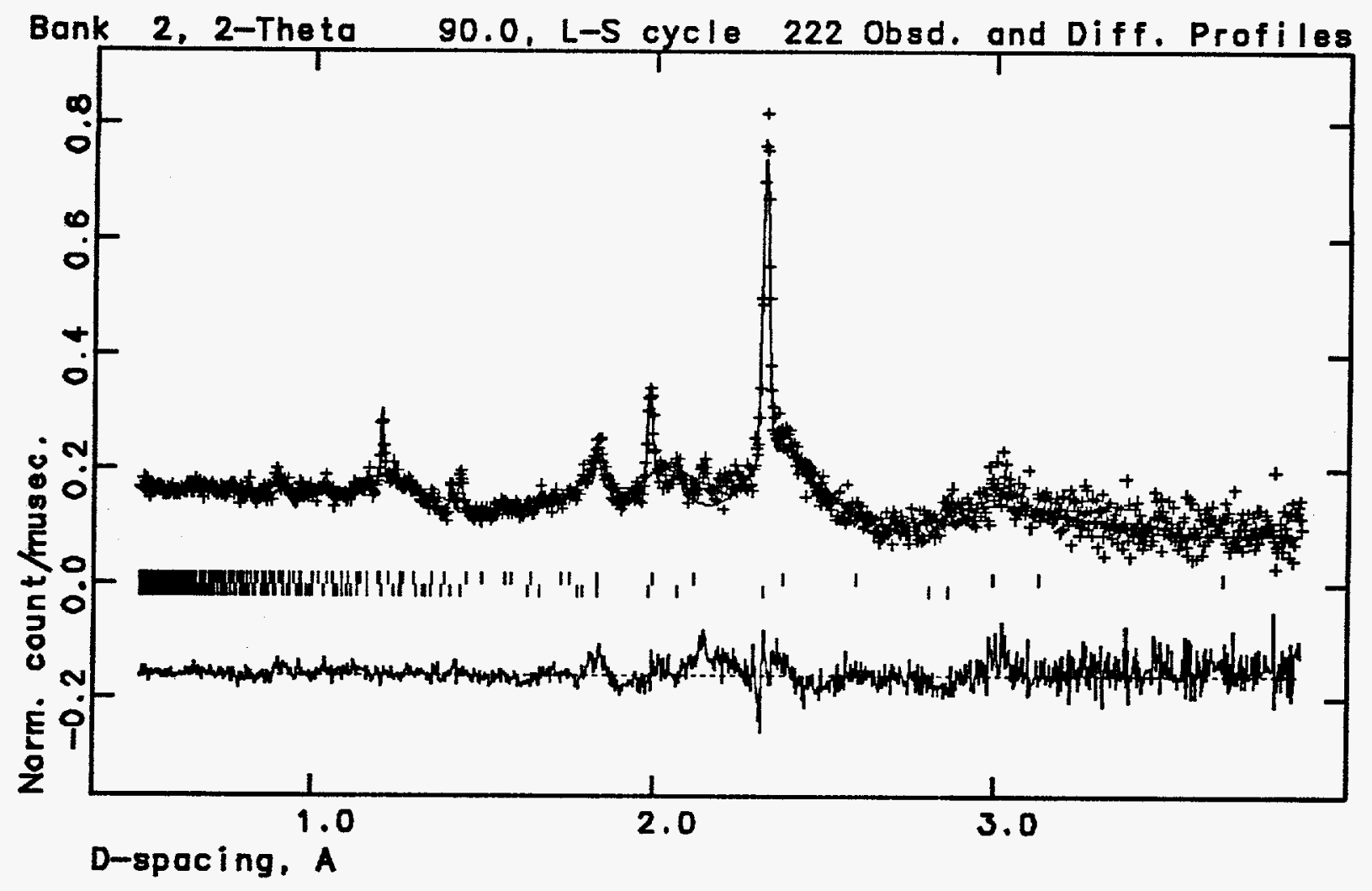

Fig. 3. Rietveld refinement for $\mathrm{PbZr}_{\mathrm{x}} \mathrm{Ti}_{1-\mathrm{x}} \mathrm{O}_{3 .,} \mathrm{x}=0.45$.

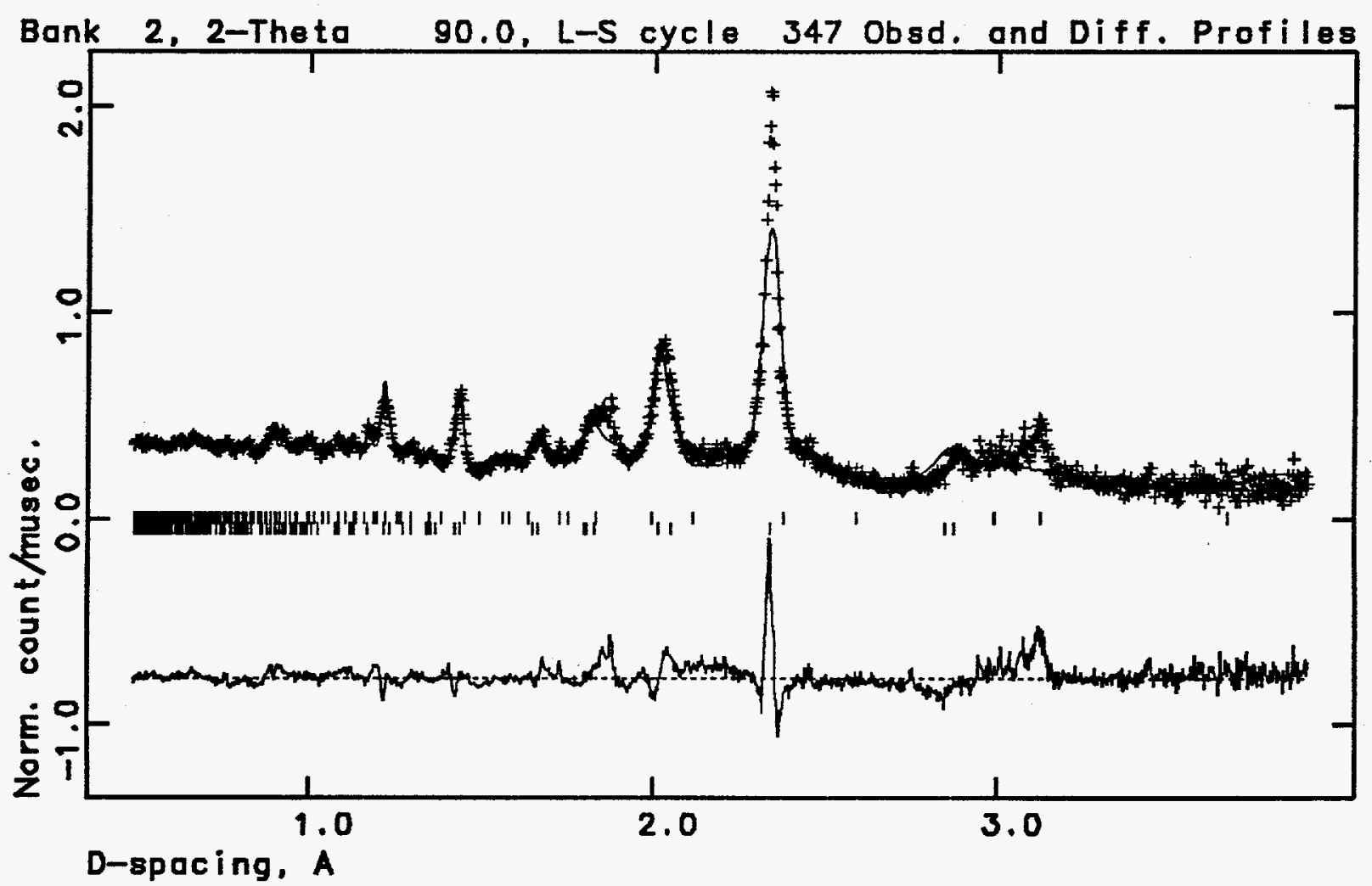


Table I. Structural parameters for three lead zirconate titanates, $\mathrm{PbTi}_{1-\mathrm{x}} \mathrm{Zr}_{\mathrm{x}} \mathrm{O}_{3}, \mathrm{x}=0.0,0.20$, and 0.45. Atomic coordinates are in $\mathrm{P} 4 \mathrm{~mm}$ for the perovskite phase with the following sites: $\mathrm{Pb}$ fixed at $(0,0,0),(\mathrm{Ti}, \mathrm{Zr})$ and $\mathrm{O} 1$ at $(1 / 2,1 / 2, \mathrm{z})$, and $\mathrm{O} 2$ at $(1 / 2,0, \mathrm{z})$ and in $\mathrm{Fd} 3 \mathrm{~m}$ (origin at $3 \mathrm{~m})$ for the pyrochlore phase with the following sites: $\mathrm{Pb}$ at $(1 / 2,1 / 2,1 / 2),(\mathrm{Ti}, \mathrm{Zr})$ at $(0,0,0), \mathrm{O} 3$ at $(\mathrm{x}, 1 / 8,1 / 8)$, and $\mathrm{O} 4$ at $(3 / 8,3 / 8,3 / 8)$. The calculated volume fraction determined from phase parameters. The site occupancy parameters, $\mathrm{pp}$, are in fraction. *

\begin{tabular}{llll}
$\mathrm{PbTi}_{1-\mathrm{x}} \mathrm{Zr}_{\mathrm{x}} \mathrm{O}_{3}$ & $\mathrm{x}=0.0$ & 0.20 & 0.45 \\
\hline & & & \\
a for $\mathrm{P} 4 \mathrm{~mm}$ & $3.9163(3)$ & $3.9714(3)$ & $4.0248(3)$ \\
$\mathrm{c}$ for $\mathrm{P} 4 \mathrm{~mm}$ & $4.1569(7)$ & $4.1345(6)$ & $4.1032(8)$ \\
vol frac for P4mm/Fd3m & $11 / 89$ & $17 / 83$ & $37 / 63$ \\
$\mathrm{U}$ for P4mm & $1.43(9)$ & $2.83(16)$ & $4.25(14)$ \\
$\mathrm{D}$ for $\mathrm{P} 4 \mathrm{~mm}$ & $90(1)$ & $115(2)$ & $39.8(3)$ \\
(Ti,Zr) z & $0.475(4)$ & $0.502(14)$ & $0.416(7)$ \\
$\mathrm{O} 1 \mathrm{z}$ & $0.886(3)$ & $0.884(3)$ & $0.929(3)$ \\
$\mathrm{O} 2 \mathrm{z}$ & $0.400(2)$ & $0.386(2)$ & $0.395(1)$ \\
$\mathrm{a}$ for Fd3m & $10.365(2)$ & $10.378(4)$ & $10.359(6)$ \\
$\mathrm{U}$ for $\mathrm{Fd} 3 \mathrm{~m}$ & $2.29(8)$ & $3.51(17)$ & $5.2(2)$ \\
$\mathrm{D}$ for $\mathrm{Fd} 3 \mathrm{~m}$ & $14.0(1)$ & $9.5(4)$ & $8.3(1)$ \\
$\mathrm{O} 3 \mathrm{pp}$ & $0.900(1)$ & $0.887(2)$ & $0.874(4)$ \\
$\quad \mathrm{x}$ & $0.3145(2)$ & $0.3107(4)$ & $0.3170(6)$ \\
$\mathrm{O}_{4} \mathrm{pp}$ & $0.600(7)$ & $0.67(1)$ & $0.76(2)$ \\
$\mathrm{R}_{\mathrm{wp}} / \mathrm{R}_{\mathrm{exp}}$ & $0.0813 / 0.0569$ & $0.0987 / 0.0693$ & $0.1050 / 0.0746$ \\
reduced x & 3.94 & 1.538 & 3.858
\end{tabular}

* Lattice constants and coherent crystallite domain size (D) are $\AA$, overall thermal parameters (U: one for each phase) are in $100 \AA^{2}$, and agreement factors are in percent. Numbers in parenthesis following refined parameters represent one standard deviation in the last significant $\operatorname{digit}(\mathbf{s})$.

\section{CONCLUDING REMARKS}

Refinement of the nanocrystalline phase pyrochlore yielded quantitative results even at the small, $<100 \AA$ coherent crystallite range. Although size parameters must be considered as "effective" size values since a strain contribution was not included (and, hence might be underestimated), values are in qualitative agreement with TEM values obtained on the PZT 20/80 films. The volume-fractions should be considered as estimates since they are sensitive to broadening parameters and thus may be susceptible to systematic error. 
With respect to the question of cation solid solution, there is no evidence for ( $\mathrm{Ti}, \mathrm{Zr}$ ) exchange with $\mathrm{Pb}$ on any site. This strongly supports the system as prepared under the conditions described above preferring the growth of the pyrochlore phase from the amorphous phase rather than a defective fluorite phase. The site occupancies for the $\mathrm{O}$ at the two different crystallographic sites in the pyrochlore phase seems to be the same for all three samples suggesting that the larger $\mathrm{Zr}$ ion relative to the smaller $\mathrm{Ti}$ ion does not enhance any ordering effect on the anions. These results suggest that the precursor solution chemistry may be important when one compares our IMO PZT gel-derived materials with those of Speck and coworkers [2] which were prepared using a methoxyethanol based process[9]. Further comparing the rapid thermally processed IMO films[5] to similar work by Lakeman et al. [10], who used the methoxyethanol process, it appears that the IMO films crystallize at lower temperatures. This may result in greater cation order for the IMO processed films.

\section{ACKNOWLEDGEMENTS}

The authors wish to acknowledge and thank J. W. Richardson and R. L. Hitterman of Argonne for their assistance and time. Work is supported by the U. S. DOE under contract \#DE-AC04$76 \mathrm{DP} 00789$ at Sandia and under contract \#W-7405-ENG-36 at Los Alamos. IPNS at Argonne is funded as a national user facility by the office of Basic Energy Sciences, Division of Material Sciences, under contract \#W-31-109-ENG-38.

\section{REFERENCES}

1. see H 7.2 and H 7.3 San Francisco 1994 MRS and I2-5.9 Boston 1994 MRS meetings.

2. A. P. Wilkinson, J. S. Speck, A. K. Cheetham, S. Natarajan and J. M. Thomas, Chem. Mater. 6, 75 (1994).

3. O. Yamaguchi, T. Fukuoka, and Y. Kawakami, J. Mater. Science Lett. 9, 958 (1990).

4. C. K. Kwok and S. B. Desu, Appl. Phys. Lett. 60, 1430 (1992).

5. J. A. Voigt, B.A. Tuttle, T.J. Headley, M.O.Eatough, D.L. Lamppa, and D. Goodnow, Mat. Res. Soc. Symp. Proc. 310, 15 (1993).

6. R.W.Schwartz, B.C. Bunker, D. Dimos, R.A. Assink, D.R.Tallant, I. Weinstock, and D.M. Haaland in Proc of 3rd Int. Symp. on Integrated Ferroelectrics 535 (1991).

7. G. Yi, Z. Wu, and M. Sayer, J. Appl.Phys. 642717 (1988).

8. A. C. Larson and R. B. VonDreele, Los Alamos Natl Lab Report No. LAUR 86-748 (1986).

9. K.Budd, S.Dey, and D.A. Payne, Proc. Br. Ceram. Soc. 36, 107 (1986).

10. C. Lakeman and D.A. Payne, Proc. Ninth IEEE Sym. on Applications of Ferroelectrics, Penn State Univ. Aug 10-14, (to be published). 